\title{
Label effects in social interaction experiments ${ }^{1}$
}

E. ALAN HARTMAN, ${ }^{2}$ Michigan State University, East Lansing, Mich. 48823

Possible response biases of $S s$ with respect to labels were investigated. The Ss were found to have specific preferences within several of the label sets used in previous social interaction experiments. Some alternative labels were tested and the triad of Argon, Boron, and Krypton was found to be least reactive.

In many experiments in the social sciences, it is necessary to label objects or persons to which a $S$ is required to respond. Social scientists have long been aware of the extraneous effects of the "natural" names that these target persons or objects bring into the experimental situation (Ebbinghaus, 1885; Glaze, 1928; Guetzkow, 1962). This concern has centered mainly on possible response preferences of Ss, where such preferences were based solely on the names of the target persons or objects. For example, Siegel (1957) found that Ss preferred even numbers on a die when choosing between odd and even in a game of chance.

To avoid possible contamination effects due to the individual names of the target persons or objects, many researchers have employed artificial labels in place of real names (Kline, 1968; Cole, 1969; Siegel, 1957; Hermann \& Hermann, 1969; Burgess \& Robinson, 1969; Vinacke \& Arkoff, 1957; Vinacke, Crowell, Dien, \& Young, 1966; Vinacke, Lichtman, \& Cherulnik, 1967). The assumption in all of the above studies was that $S s$ did not have differential response preferences for the labels used. The replacement of individual names by labels in social-interaction experiments has the effect of standardizing the situation by using the same names for all of the groups run in the experiment. This replacement, however, does not mean that the Ss will not have preferences over the set of labels chosen.

In past research, primarily two types of labels have been used: nonsense syllables and letters of the alphabet. Glaze (1928) investigated the association value of nonsense syllables. Many researchers since then have used the norms developed by Glaze to choose what they thought were neutral artificial labels. For example, zero-association-value nonsense syllables were used to designate the three Ss in a coalition-formation study performed by Kline (1968). An example of the second type was the use of $A, B$, and $C$ in a number of coalition-formation studies
(Cole, 1969; Vinacke \& Arkoff, 1957; Vinacke et al, 1966; Vinacke et al, 1967). In these studies, as well as in Kline's, no evidence was offered to support the assumption that the labels chosen eliminate response biases in Ss. It may be that some preference structure did exist for these labels.

A more specific example of the use of artificial labels is an experiment performed by Cole (1969). It was an investigation of conflict and coalition formation through the use of the experimental paradigm called the "truel." At the beginning of this three-person game, each player was assigned a certain number of points and an ability to take a certain number of points away from one of the other two players. The game consisted of moves, with each player taking points away from one of the other two players. These points were removed from the game and given to no one. The game was ended when only one player had points remaining: He was the winner. To solve the problem of possible response preferences of the Ss, Cole used the letters $A, B$, and $C$, but offered no evidence that these artificial labels would, in fact, eliminate such bias.

The present research examined the degree to which this assumption by Cole (and others) was tenable. In addition, it examined possible less reactive alternatives to $A, B$, and $C$.

\section{METHOD}

Nineteen groups, each composed of three male $\mathrm{Ss}$, were recruited from introductory courses of psychology at Michigan State University. None of the Ss knew the others prior to the experiment. At the completion of the experiment, the Ss were questioned as to their knowledge of which players had which labels. If any member professed knowledge of another player's label, that group was discarded from the analysis. Three such groups were discarded.

To test for possible response preferences, an experimental paradigm similar to that used by Cole was employed. Every player began each game with three points and on each move was allowed to take a point away from one other player. This procedure allowed the effects of labels to be analyzed independently of the power

The Eight Label Sets Tested

\begin{tabular}{llllllll}
\hline 1 & 2 & 3 & 4 & 5 & 6 & 7 & 8 \\
\hline Bill & Dave & Jim & Gray & Argon & Fervid & A & VAF \\
Bob & Dan & Jerry & Green & Boron & Frosty & B & ZEG \\
Barry & Dick & Jack & Gold & Krypton & Far & C & YAV \\
\hline
\end{tabular}

(points possessed and ability to take points away) of the participants.

During the entire experiment, the Ss were seated at a table but separated from each other by partitions. They were unable to see each other, but they faced the $\mathbf{E}$ from the long side of a rectangular table. An abacus-like arrangement was used as a scoreboard and was mounted on the wall directly behind and above the $E$, in full view of the Ss.

At the beginning of the experiment, the instructions were read to the Ss, and all questions regarding the playing of the game were answered. The labels were varied from game to game and only the $E$ knew which Ss had which labels. The labels were listed in a vertical line to the left of the scoreboard, and the points (represented by circular disks) were placed to the right of them on a horizontal rod.

The eight sets of labels tested are presented in Table 1. The sixth set was taken from an experiment by Jenkins, Russell, \& Suci (1958), in which Ss rated words by the semantic differential technique. These three adjectives were rated 3.5 on a 7 -point evaluative scale (ranging from 0 to 7 , with good on one end and bad on the other). The seventh set of names is made up of nonsense syllables used by Kline (1968), with the eighth set being composed of the letters used by Cole (1969), Vinacke \& Arkoff (1957), and Vinacke et al $(1966,1967)$. The remainder of the sets were selected in an attempt to test various, relatively common, real names in an experimental situation.

Four combinations of these eight label sets were constructed, with each label set appearing in two different combinations. For each of these combinations four groups of Ss were used, with each group receiving a different order of label sets in a Latin-square design.

Within every group of Ss, each label set each $S$ and each position on the scoreboard to be represented by each label once. Every presentation of a label set was separated by presentations of each of the other three sets.

\section{RESULTS AND DISCUSSION}

Since only the first move precludes any attacks being made in retaliation to a previous attack, and since on this move the Ss have equal power, only points taken away on this move were analyzed by a chi-square goodness-of-fit test. Since each was repeated three times, thus allowing 
player must choose between two attack possibilities, and since the labels are assumed to attack randomly, the probability of either attack being made is .5. With 24 attacks per label available for analysis, the expected frequency for each chooser-chosen cell was 12 .

Because each $S$ contributed one attack for each of the labels used in his group, only the chi squares within the labels are independent and, therefore, only the chi square for each label was used in the test. The degrees of freedom for each label was one, due to the marginal constraint that the expected frequency be equal to 12. This restriction in analysis is not crucial, because an entire set can be rejected for social-interaction experiments if just one of its labels has a chi square significant at the .05 level.

The most interesting results of the experiment are the chi squares for the two label sets, A-B-C and VAF-ZEG-YAV. The first of these sets was used by Cole (1969) and Viancke et al $(1966,1967)$ and the second by Kline (1968). One label within each of these sets (C and YAV) yielded a significant chi square $(4.16, p<.05)$. Of the remaining labels in both sets, $A$ and $B$ in the first set had completely random behavior patterns, while VAF and ZEG were a little less random with chi squares of $.66(\mathrm{p}>.5)$ and $.16(\mathrm{p}>.75)$, respectively.

The BILL-BOB-BARRY set had the labels (BILL and BOB) with the largest chi square $(6.00, p<.01)$. The other two sets of boys' names and the set of colors all had at least one label with a large enough chi square to be questionable. In each case, the chi square was 2.66 , with a value of 2.71 needed for $\mathrm{p}<.1$.

The two label sets remaining, F E R VID - F R O S T Y - FAR and ARGON-BORON-KRYPTON, had no label with a chi square larger than $.66(\mathrm{p}>.75)$. The entire ARGON-BORON-KRYPTON set had no chi square larger than .16 $(\mathrm{p}>$.75).

Overall, the results of this study indicate that the untested use of labels for the purpose of removing Ss' response biases does not guarantee random choice behavior. The label set used by Cole (1969) and Vinacke et al $(1966,1967)$ and the set used by Kline (1968) were shown, in the present research, to have response biases in the ambiguous all-equal situation. The results of their studies, however, do not present an examination of the degree to which these biases affected behavior when the power of the players differed. However, the mere fact that there are response biases in the ambiguous situation and that response biases may be present in the unambiguous cases is enough to warrant further tests of the labels used in social-interaction experiments.

\section{REFERENCES}

BURGESS, P. M., \& ROBINSON, J. A. Alliances and the theory of collective action: A simulation of coalition processes. In J. N. Rosenau (Ed.), International politics and foreign policy. (Rev. ed.) New York: Free Press, 1969. Pp. 640-650.

COLE, S. G. An examination of the power inversion effect in three person mixed-motive games. Journal of Personality \& Social Psychology, 1969, 11, 50-58.

EBBINGHAUS, H. Uber das Gedachtnis. Translated by $\mathrm{H}$. A. Ruger and C. E. Bussenius as Memory: $A$ contribution to experimental psychology. New York: Dover, 1964.

GLAZE; J. A. The association value of nonsense syllables. Journal of Genetic Psychology, $1928,35,255-269$

GUETZKOW, H. Simulation in the study of inter-nation relations. In $\mathrm{H}$. Guetzkow (Ed.), Stimulation in the social sciences. Englewood Cliffs, N. J: Prentice-Hall, 1962. Pp. 82-93.

HERMANN, C. F., \& HERMANN, M. G. An attempt to simulate the outbreak of World War I. In J. N. Rosenau (Ed.), International politics and foreign policy. (Rev, ed.) New York: Free Press, 1969. Pp. 622-639.

JENKINS, J. J., RUSSELL, W. J., \& SUCI, G. J.
An atlas of semantic profiles for 360 words American Journal of Psychology, 1958, 71, 688-699.

KLINE, D. The effect of bargaining sequence and type of pay-off upon coalition structure and stability in the triad. Technical Report No. 2. Human Learning Research Institute, Michigan State University, 1968

SIEGEL, S. A method for obtaining an ordered metric scale. In S. Messnick and A. H. Brayfield (Eds.), Decision and choice. New York: McGraw-Hill, 1964. Pp. 61-70.

VINACKE, W. E., \& ARKOFF, A. An experimental study of coalitions in the triad. American Sociological Review, 1957, 22, 406-414.

VINACKE, W. E., CROWELL, D. C., DIEN, D., $\&$ YOUNG, $V$. The effect of information about strategy on a three person game. Behavioral Science, 1966, 11, 180-189.

VINACKE, W. E., LICHTMAN, C. M., \& CHERULNIK, P. K. Coalition formation under four different conditions of play in a three person competitive game. Journal of General! Psychology, 1967, 77, 165-176.

$$
\text { NOTES }
$$

1. This research was funded by a grant from the Air Force Office of Scientific Research (F44620-69-C-0114).

2. I am grateful to Dr. James L. Phillips and Dr. Lawrence Messe for their help in preparing this paper.

\section{Short-term association recall as a function of number and type of retention interval tasks 1}

C. JAMES SCHEIRER and JAMES F. VOSS, University of Pittsburgh, Pittsburgh, Pa. 15213

In a single-association short-term memory task, four retention-interval activities involving manipulation of numbers were employed, with retention intervals of 32,64 , and $128 \mathrm{sec}$. In the 64and 128-sec intervals, conditions involving two or four tasks of $32 \mathrm{sec}$ each also were employed. The results indicated that number of task shifts in a retention interval did not significantly retard performance and that a number-classification task yielded recall performance significantly superior to addition, subtraction, and counting backwards.
The purpose of the present experiment was to determine if the type of task and the number of shifts in task during the retention interval influence recall performance in a Peterson-type (Peterson \& Peterson, 1959) short-term memory paradigm. That the type of task employed in a retention interval may be a factor in producing differences in recall performance has been demonstrated, e.g., Posner \& Konick (1966). Their results suggested that a classification task involving a relatively high degree of information processing led to poorer recall than other tasks, such as counting backwards or addition, that had a lower processing requirement. The question of whether shifts in the tasks influence forgetting has yet to be 